\title{
Analysis of Carbides in Multi-component Cast Iron Design Based on High Entropy Alloys Concepts
}

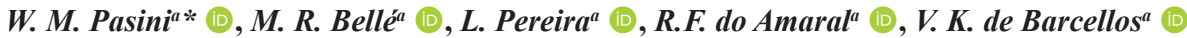 \\ ${ }^{a}$ Universidade Federal do Rio Grande do Sul, Centro de Tecnologia, Laboratório de Fundição, Porto \\ Alegre, RS, Brasil
}

Received: August 31, 2020; Revised: December 21, 2020; Accepted: January 25, 2021

\begin{abstract}
Nowadays, the concept of high entropy alloys (HEAs) has expanded the limits of metallurgy and high-quality metallurgical HEAs ingots have already been successfully obtained on an industrial scale. High Chromium Cast Irons (HCCI) and Multi-Component Cast Irons (MCCI) are known to be a useful material for applications when abrasion resistance is required. Inspired by the concepts of high-entropy alloys, a base HCCI was modified, by adding other carbide-forming elements, at concentrations higher than what is currently used, in order to develop a new class of white cast iron, High Entropy White Cast Iron (HEWCI). The characterization of carbides precipitated during the HEWCI solidification was performed by scanning electron microscopy, energy dispersive spectroscopy, electron backscattered diffraction (SEM/EDS/EBSD) and X-ray diffraction (XRD). With the characterization techniques employed, the as-cast microstructure obtained of HEWCI is composed of approximately $50 \%$ of austenite matrix and $50 \%$ of different types of carbides, $\mathrm{MC}, \mathrm{M}_{7} \mathrm{C}_{3}$ and $\mathrm{M}_{2} \mathrm{C}$ carbides.
\end{abstract}

Keywords: High entropy alloys, High Chromium Cast Irons, Multi-component Cast Irons, Carbide-forming elements.

\section{Introduction}

High Chromium Cast Irons (HCCIs) and Multi-Component Cast Irons (MCCI) are resistant materials used in applications in specific environments, including hot working mill rolls in the steel industry and pulverizing mill rolls in the mining and cement industry ${ }^{1-3}$. The superior resistance to abrasive wear is mainly the result of their high-volume fraction of hard carbides. MCCI and HCCI alloys contain alloying elements such as $\mathrm{Cr}, \mathrm{V}, \mathrm{Mo}, \mathrm{W}, \mathrm{Nb}$, and their $\mathrm{C}$ content is relatively higher than some of the high-speed tool steels. Hard Carbides $\mathrm{MC}, \mathrm{M}_{2} \mathrm{C}, \mathrm{M}_{6} \mathrm{C}, \mathrm{M}_{7} \mathrm{C}_{3}$ can be precipitated as proeutectic and/or eutectic carbides during solidification ${ }^{3,4}$. Due to the demands for upgrading productivity and improving the quality of products, new types of abrasion-resistant alloys have been developed to replace and promote better performance than conventional materials ${ }^{1-4}$.

Through the history of metallurgy, the development of metallic alloys has been modeled based on the 'base element approach', where one principal element act as the matrix and other elements are incorporated for property/ processing enhancement ${ }^{5}$. Recently, Cantor et al. ${ }^{5}$ and Yeh et al. ${ }^{6}$, in independent researches, proposed a new alloy design concept. A novel approach for alloy design is motivated by the exploration of the uncharted central regions of multicomponent phase diagrams and it involves the mixing of multiple elements, five or more, resulting in the so-called "High Entropy Alloy", ${ }^{7,8}$

Originally the HEAs concept was based on the search for single-phase solid solutions alloys modeled as an ideal

*e-mail: willian.pasini@ufrgs.br solution, therefore, the configurational entropy per mole could be expressed as:

$\Delta \mathrm{S}_{\text {conf }}=-\mathrm{R} \sum \mathrm{x}_{\mathrm{i}} \ln \mathrm{x}_{\mathrm{i}}$

where $\mathrm{R}$ is the gas constant and $\mathrm{xi}$ is the mole fraction of the $\mathrm{i}^{\text {th }}$ element. Based on Eq. (1) it is possible to conclude that the alloy configurational entropy increases as the number of alloy elements increases. Considering the first criteria of Yeh et al., the minimum number of major elements in HEAs is five, where, at five-element equiatomic alloys the $\Delta \mathrm{S}_{\text {conf }}$ is $1.61 \mathrm{R}$. Based on this, a boundary condition of $\Delta \mathrm{Sconf}$ $1.5 \mathrm{R}$ was defined as a reasonable lower limit for $\mathrm{HEAs}^{7-11}$.

However, since the first studies, most of the recent researches is based on multi-phase HEAs, not included by the first definition. For this reason, to expand the frontiers of the HEA research field new terms were defined, as Complex Concentrated Alloys, Multi-Principal Element Alloys (MPEAs), and Entropy-Enhanced Conventional Alloy (EECA). These news terms are more inclusive and cover a greater number

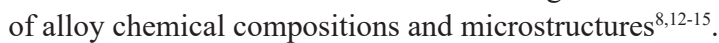

The approach of solute entropy enhancement has been applied to conventional alloys to develop various high-entropy steels and high-entropy cast iron. Raabe et al. ${ }^{16}$ designed high entropy steels based on the Fe-Mn-Al-Si-C system introducing solutes to the Fe-Mn-C system and achieving a single-phase homogeneous FCC phase. A different strategy was introduced by Pushin et al. ${ }^{17}$ where a new type of high-entropy steel was designed by alloying many strong carbide-forming elements $(\mathrm{Cr}, \mathrm{Mo}, \mathrm{W}$, and $\mathrm{V})$ to the $\mathrm{Fe}-\mathrm{C}$ 
system at the same time. A similar modification was made by Wang et al. to white cast iron ${ }^{15-17}$.

Y.P. Wang and co-workers proposed to modify the chemical composition of conventional Hypereutectic and Hypoeutectic High Chromium Cast Iron (HCCI) based on the basic concepts of High Entropy Alloy to develop the hybrid HCCI with better wear resistance in comparison with traditional $\mathrm{HCCI}^{18,19}$. However, the hybrid HCCI developed by Wang et al., was formed for 5 or more major elements and did not achieve $\Delta \mathrm{S}_{\text {conf }}>1.5 \mathrm{R}$.

Currently, high-quality industrial-scale HEA ingots were successfully obtained by the casting process. However, in most of these cases, these alloys are produced in furnaces with an inert atmosphere chamber, to avoid liquid metal contamination. For this reason, the development of HEAs for casting in the air atmosphere offers ease of fabrication and use of HEAs as engineering materials and, simultaneously, makes the production of HEAs more cost-effective ${ }^{20,21}$.

In this study, the High Entropy Alloy approach was applied to modify a High Chromium Cast Iron, by adding a high quantity of carbide-forming elements to the material, including $\mathrm{V}$ as a strong carbide former and Mo as a less strong carbide former. In order to achieve an Entropy-Enhanced Conventional Alloy, the atomic concentrations of carbide formers added to molten metal were intentionally higher than what has conventionally used. Carbides former $(\mathrm{Cr}$, $\mathrm{V}$, and $\mathrm{Mo}$ ) were added at atomic fraction superior to $5 \%$ in agreement with high entropy concepts. This study was focused on alloy design and analysis of phases precipitated during the solidification of a new abrasion-resistant alloy called in this work High Entropy White Cast Iron (HEWCI), with a configuration entropy at liquid state superior to $-1.5 \mathrm{R}$.

\section{Materials and Methods}

To achieve the chemical composition of the HEWCI, the alloying elements $\mathrm{Cr}, \mathrm{Mo}, \mathrm{Mn}, \mathrm{V}, \mathrm{Nb}$, and Co were added to the melt of hypoeutectic HCCI scrap in the form of Fe-Cr, Fe-V, Fe-Mo, Fe-Mn, Fe-Nb, pure Co and carbon source in an $8 \mathrm{~kg}$-capacity coreless induction furnace without protection atmosphere. The melt was subsequently heated up to $1500^{\circ} \mathrm{C}$ and removal of any dross or slag was performed. The alloy was poured at $1450^{\circ} \mathrm{C}$ in a thermal-analysis sand cup instrumented with Type-K thermocouple, with an aim to obtain the cooling curve and the sequence of phases formed during solidification by the cooling curve analysis. The alloy composition and configurational entropy of mixing at liquid state are shown in Table 1.

The identification of precipitated phases was performed using X-ray diffraction (XRD) analysis using a diffractometer with monochromatic $\mathrm{Cu} \mathrm{K}$ radiation. The $2 \theta$ scan angles varied from $5^{\circ}$ to $120^{\circ}$ and current and voltage settings were $30 \mathrm{~mA}$ and $40 \mathrm{KV}$. The microstructure of the alloy was examined using Scanning Electron Microscopy (SEM). SEM analysis was performed in two different microscopes using different techniques such as secondary electrons images (SEI), Electron Back-Scatter Diffraction (EBSD) maps, IQ pattern quality maps, X-ray mapping performed at a Zeiss Auriga Field Emission Gun SEM and back-scattered electron images (BSE). The chemical composition of the isolate carbides was analyzed by EDS at Zeiss EVO 10 MA SEM.

EBSD maps and IQ pattern maps techniques were applied in order to quantify and separate the phase fraction on the microstructure of as-cast sample. To analyze the distribution of various elements within and between the austenite dendrites as well as eutectic carbides, X-ray mapping, line scan, area, and point EDS analysis was performed.

\section{Results and Discussion}

\subsection{Microstructure characterization}

Microstructure observations obtained by electron microscopy (Back-scattered Electron Image) revealed the presence of four distinctive constituents, as shown in Figure 1.

Figure 2 shows the results of phase identification by $\mathrm{X}$-ray diffraction (XRD) on the as-cast alloy. The XRD results show peaks of austenite and carbides $M C, M_{2} C$, and $M_{7} C_{3}$. EBSD maps and IQ pattern maps techniques were applied in order to quantify and separate the phase fraction on the microstructure of as-cast sample, as exemplified by Figure 3 .

The average fraction and description of the morphology of each phase of the as-cast specimen at three different regions of the sample are summarized in Table 2.

According to the microstructures and XRD results, $\mathrm{M}_{7} \mathrm{C}_{3}$ carbide (red in Figure 3) shows two different morphologies, which started with the formation of a rod-shaped primary $\mathrm{M}_{7} \mathrm{C}_{3}$ carbide(proeutectic), followed by an eutectic transformation that results in the formation of $\mathrm{M}_{7} \mathrm{C}_{3}$ with fine morphology (Blade-like), as can be seen in Figure 4. The carbide morphologies presented at HEWCI are in accordance with the results from Doğan et al. ${ }^{1}$ and Liu et al. ${ }^{22}$.

Morphology of the MC carbide is normally classified into 4 types of morphology: dendritic/chunky of primary carbides and petal-like, nodular and coral-like types for eutectic carbides ${ }^{23}$. The $\mathrm{M}_{2} \mathrm{C}$ carbide is classified into two categories of eutectic, regular-complex eutectic with lamellar/fibrous morphology and irregular eutectic with plate-like morphology $y^{23-25}$. The type and morphology of carbides depends on chemical composition of liquid metal, particularly carbon and vanadium, as well as molybdenum and other carbide formers.

\subsection{Solidification path and Thermo-analysis}

A cooling curve of the HEWCI is shown in Figure 5. On the cooling curve, three reactions, arrest points indicated by $\mathrm{R}_{1}, \mathrm{R}_{2}$, and $\mathrm{R}_{3}$, appeared at $1286^{\circ} \mathrm{C}, 1187^{\circ} \mathrm{C}$, and $1156^{\circ} \mathrm{C}$, respectively. The determination of the solidification reaction

Table 1. Chemical composition of cast alloy.

\begin{tabular}{ccccccccccc}
\hline & $\mathbf{C}$ & $\mathbf{C r}$ & $\mathbf{M o}$ & $\mathbf{V}$ & $\mathbf{M n}$ & $\mathbf{S i}$ & $\mathbf{C o}$ & $\mathbf{N b}$ & $\mathbf{F e}$ & $\boldsymbol{\Delta} \mathbf{S}_{\text {conf }}(*)$ \\
\hline \%Wt & 3.45 & 21.4 & 11.15 & 7.3 & 6.3 & 1.8 & 2.0 & 0.6 & 45.9 & - \\
\hline \%At & 14.4 & 20.6 & 5.8 & 7.1 & 5.7 & 3.1 & 1.7 & 0.3 & 41.3 & $-1.68 \mathrm{R}$ \\
\hline
\end{tabular}

$\left.{ }^{*}\right) \Delta \mathrm{S}_{\text {conf }}$ calculated based on Equation 1. 


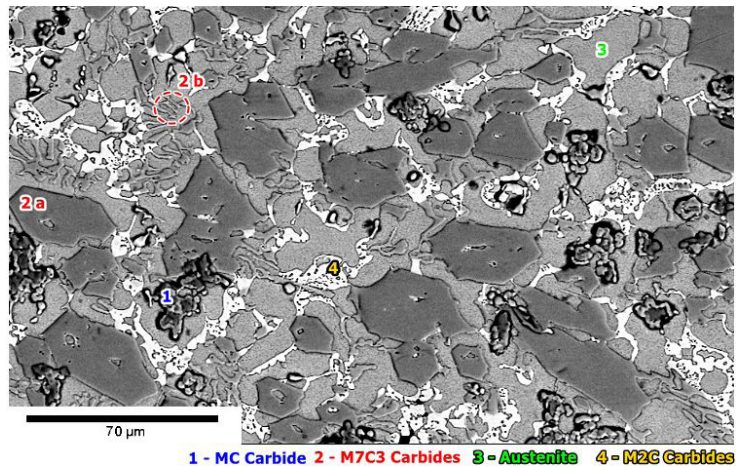

Figure 1. Back-scattered Electrons image of as-cast HEWCI microstructure.

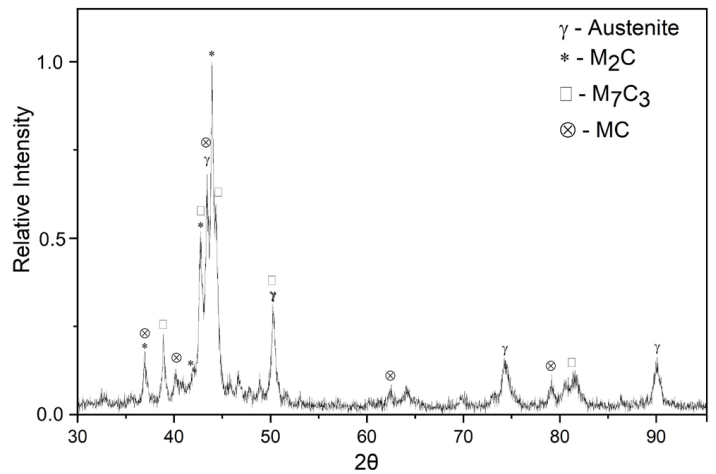

Figure 2. Identification of austenite, $\mathrm{MC}, \mathrm{M}_{2} \mathrm{C}$ and $\mathrm{M}_{7} \mathrm{C}_{3}$ phases by DRX. at each arrest point was carried out by observing the carbides morphologies (obtained as-cast microstructure) and comparing it with thermal-analysis of solidification sequence of multi-components cast iron and high-chromium previous published $\mathrm{d}^{4,23,26-28}$.

The results of XRD analysis show peaks of austenite and $\mathrm{MC}, \mathrm{M}_{7} \mathrm{C}_{3}$, and $\mathrm{M}_{2} \mathrm{C}$ carbides. Vanadium and niobium act as strong carbide-forming elements, since, traditionally, they form stable MC carbide at elevated temperatures in equilibrium with the liquid. Temperature range of $\mathrm{MC}$ (vanadium-rich carbides) precipitation in Multi-component cast irons was investigated by Wu et al. ${ }^{27}$, Sasaguri $\mathrm{N}^{26}$, and Matsubara $\mathrm{Y}^{4}$ in previous studies which evaluated different chemical compositions of a multi-component system with a high content of vanadium $(5-10 \% \mathrm{wt})$. The results indicated the $\mathrm{MC}$ precipitation temperature occurs above $1300^{\circ} \mathrm{C}$, as summarized in Table 3.

High Chromium Cast Irons (HCCI) were investigated in previous studies by Thorpe and $\mathrm{Chicco}^{28}$, and a metastable liquidus surface to $\mathrm{Fe}-\mathrm{Cr}-\mathrm{C}$ system has been experimentally determined using Differential Thermal Analysis technique during heating and cooling on alloys with a predetermined chemical composition (up to $40 \%$ wt. $\mathrm{Cr}$ and up to $6 \% \mathrm{wt}$. C). The determination of the precipitated phase in $\mathrm{R}_{1}$ reaction was carried out by construction of atomic percentage metastable $\mathrm{Fe}-\mathrm{Cr}-\mathrm{C}$ liquidus surface diagram, showed in Figure 6, with predetermined chemical composition range (5 to $25 \%$ at. $\mathrm{Cr}$ and 10 to $20 \%$ at. C). The analysis of chromium and carbon plotted on the metastable Fe-Cr-C liquidus surface diagram is detailed in Figure 6b.
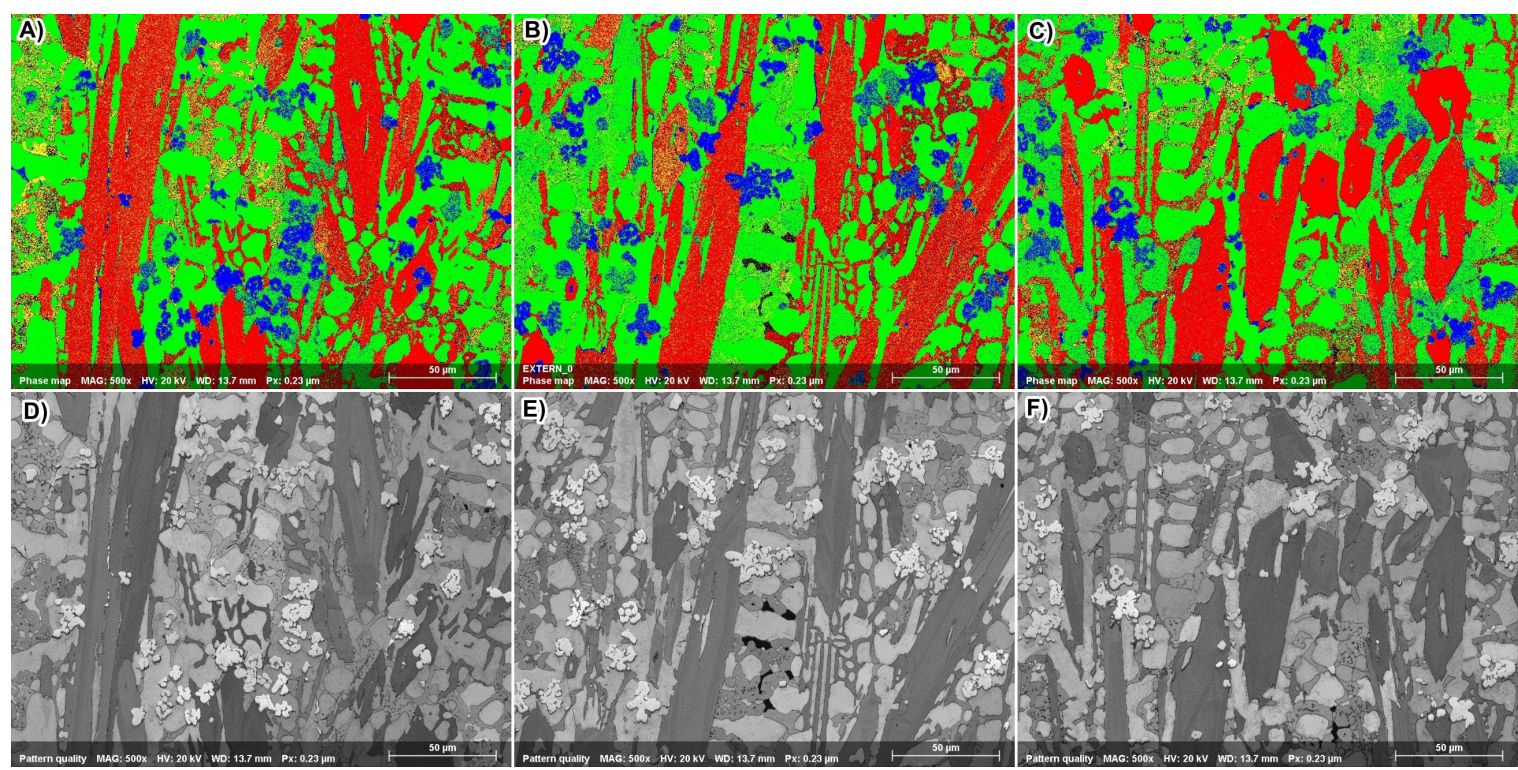

Figure 3. Result of EBSD mapping (A-B-C) and IQ pattern (D-E-F) techniques - $\left(\mathrm{M}_{7} \mathrm{C}_{3}\right.$ red, $\mathrm{MC}-\mathrm{Blue}, \mathrm{M}_{2} \mathrm{C}-$ yellow, Austenite - green).

Table 2. Phase fraction according EBSD Map and Phase Morphology.

\begin{tabular}{lccccc}
\hline & Austenite & MC & $\mathbf{M}_{7} \mathbf{C}_{3}$ & $\mathbf{M}_{2} \mathbf{C}$ & Zero solutions \\
\hline $\begin{array}{l}\text { Phase Fraction (\%) } \\
\text { average }\end{array}$ & $47.4 \pm 1.5$ & $8.7 \pm 0.6$ & $31.6 \pm 1.5$ & $7.3 \pm 0.9$ & $5.1 \pm 0.5$ \\
\hline Morphology & Dentritic & Dendritic & Rod-Like & Fibrous \\
\hline & Eutectic & Chunky & Blade-Like & & \\
\hline
\end{tabular}




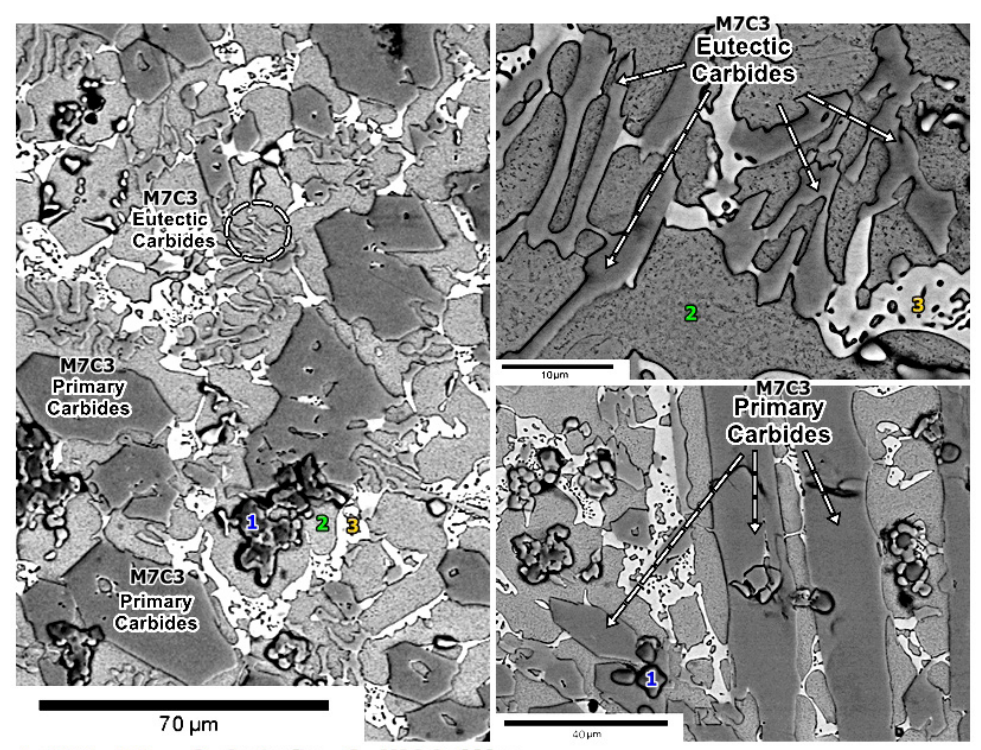

1- MC Carbides 2-Amstenfie 3-M2S Carbides

Figure 4. Morphology of Primary $\mathrm{M}_{7} \mathrm{C}_{3}$ and Eutectic Carbides.
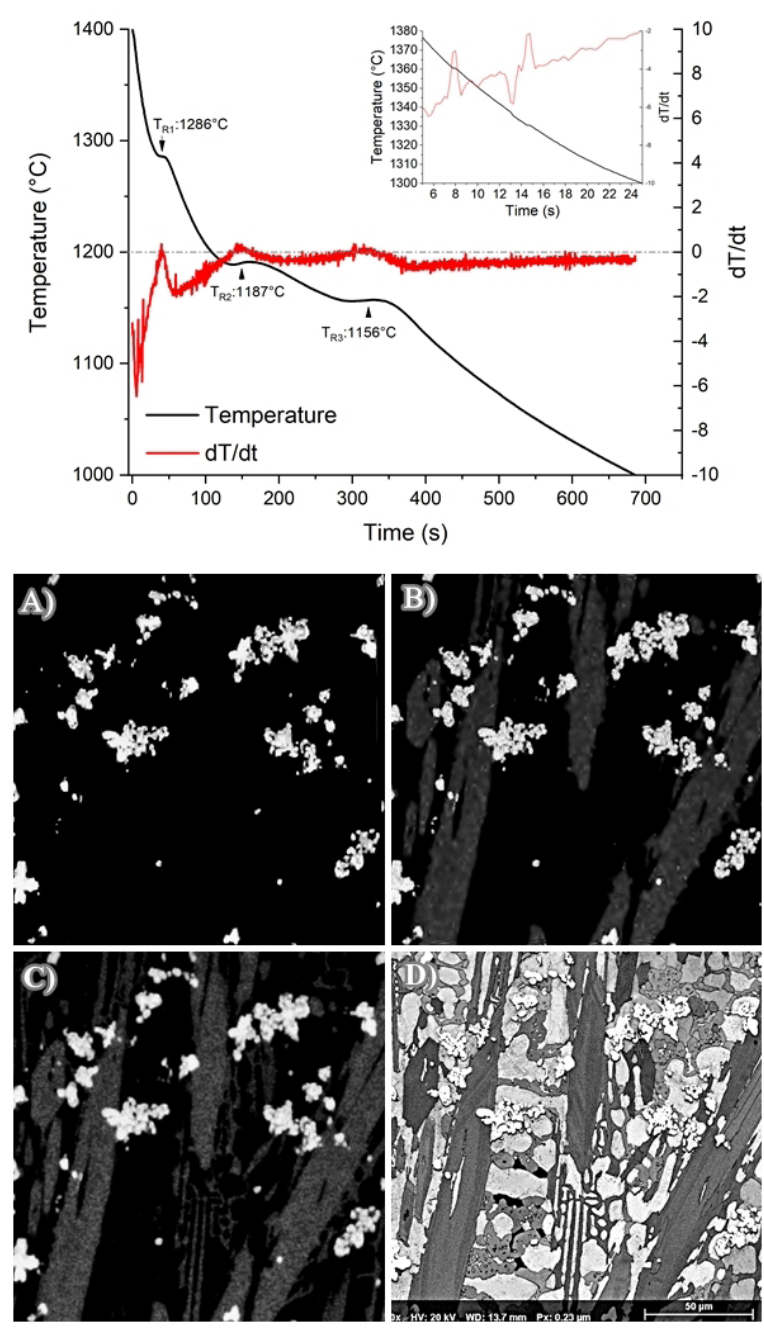

Figure 5. A thermal analysis curve (top) and schematic representation of solidification stages of HEWCI (bottom) edited by EDS mapping of $\mathrm{V}$ and Fe concentrations; A) representation of $\mathrm{MC}$ proeutectic carbides; $\mathrm{B}$ ) representation of $\mathrm{M}_{7} \mathrm{C}_{3}$ proeutectic carbides; C) representation of $\mathrm{M}_{7} \mathrm{C}_{3}$ eutectic carbides; D) As-cast HEWCI microstructure with all phases, including $\mathrm{M}_{2} \mathrm{C}$ and austenite. 
Table 3. MC carbide precipitation temperatures in Multi-Component Cast Iron.

\begin{tabular}{lccc}
\hline $\begin{array}{c}\text { Alloy Composition } \\
{[\% \mathbf{w t}]}\end{array}$ & $\begin{array}{c}\mathbf{V} \\
{[\% \mathbf{w t}]}\end{array}$ & $\begin{array}{c}\text { Temperature } \\
{\left[{ }^{\circ} \mathbf{C}\right]}\end{array}$ & Ref \\
\hline Fe-3C-5Cr-2Mo-5Co & 5 & 1315 & ${ }^{22}$ \\
\hline Fe-3C-5Cr-2Mo-5Co & 9 & 1380 & ${ }^{22}$ \\
\hline Fe-4C-5Cr-6Mo-5W & 5 & 1385 & ${ }^{21}$ \\
\hline Fe-4C-5Cr-2Mo-2W & 5 & 1385 & ${ }^{21}$ \\
\hline Fe-3C-5Mo-5W & 10 & 1350 & 4 \\
\hline
\end{tabular}

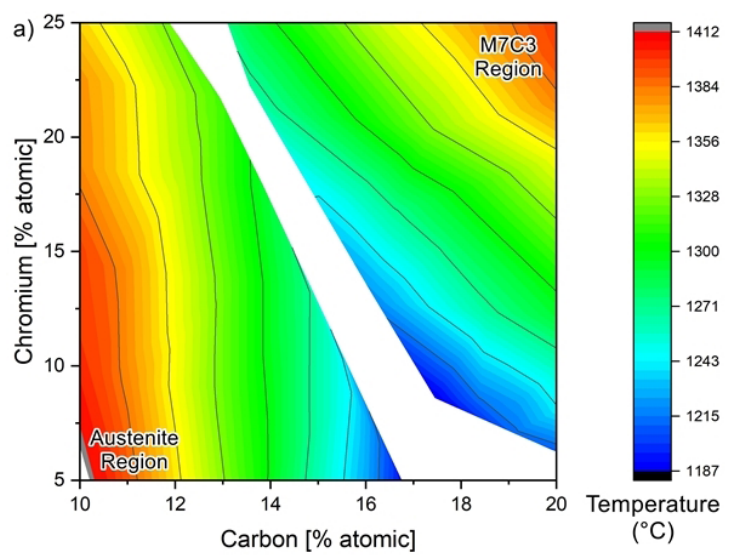

b)

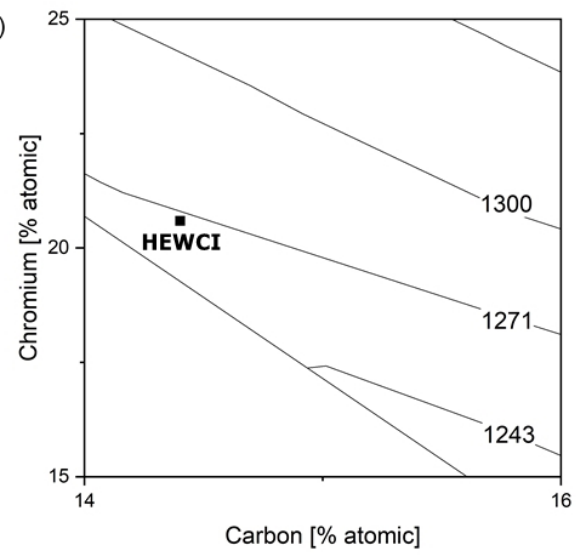

Figure 6. a) atomic \% metastable $\mathrm{Fe}-\mathrm{Cr}-\mathrm{C}$ liquidus surface diagram (austenite and $\mathrm{M}_{7} \mathrm{C}_{3}$ regions) b) Detailed view of isotherms near of region of interest (HEWCI chemical composition).

Table 4. Possible solidification sequence.

\begin{tabular}{cc}
\hline Temperature & Propable phases transformations \\
\hline$<1300^{\circ} \mathrm{C}$ & $\mathrm{L}_{1}-\mathrm{MC}_{\text {(pro-eutectic) }}+\mathrm{L}_{2}$ \\
\hline $1286^{\circ} \mathrm{C}$ & $\mathrm{L}_{2}-\mathrm{M}_{7} \mathrm{C}_{3 \text { (pro-eutectic) }}+\mathrm{L}_{3}$ \\
\hline $1187^{\circ} \mathrm{C}$ & $\mathrm{L}_{3}-\gamma+\mathrm{M}_{7} \mathrm{C}_{3 \text { (eutectic) }}+\mathrm{L}_{4}$ \\
\hline $1156^{\circ} \mathrm{C}$ & $\mathrm{L}_{4}-\gamma+\mathrm{M}_{2} \mathrm{C}$ \\
\hline
\end{tabular}

At the metastable Fe-Cr-C liquidus surface, the proeutetic carbide starts to precipitate at temperatures around $1270{ }^{\circ} \mathrm{C}$. Considering the morphology of primary carbides showed in Figure 4 and the analysis based on atomic \% metastable $\mathrm{Fe}-\mathrm{Cr}-\mathrm{C}$ liquidus surface diagram, $\mathrm{T}_{\mathrm{R} 1}$ inflection on the cooling curve indicates the precipitation of primary $\mathrm{M}_{7} \mathrm{C}_{3}$ carbides.
On the solidification behavior of high chromium cast iron and multi-component cast iron, during the growing of austenite dendrites, molybdenum is severely rejected into the liquid, enriching the interdendritic region and promoting the precipitation of Mo carbides at a lower temperature eutectic reaction. The Mo additions to High Chromium Cast Irons lead to the formation of $\mathrm{M}_{2} \mathrm{C}$ or $\mathrm{M}_{6} \mathrm{C}$ type carbides depending on the $\mathrm{Cr} / \mathrm{C}$ ratio $^{29-31}$

The HEWCI presents a $\mathrm{Cr} / \mathrm{C}$ ratio equal to 6.2 and the content of Mo dissolved in the alloy is around $11 \% \mathrm{wt}$. These values are similar to the data published by Ikeda et al. ${ }^{31}$. In these previous studies, $\mathrm{Cr} / \mathrm{C}$ ratio is equal to 6.5 , Mo content of $9.5 \%$ wt., and the last liquid to solidify results in an eutectic transformation with austenite and $\mathrm{Mo}_{2} \mathrm{C}$ at $1160^{\circ} \mathrm{C}$.

By comparing the reaction temperatures published in previous studies regarding solidification of Multi-Component Cast Iron and High Chromium Cast Iron, the cooling curve of HEWCI, and the phases presented at XRD results, it is possible to consider the solidification sequence of the HEWCI as summarized in Table 4.

The temperature of the first solidification reaction was not detected at thermal analysis since the data acquisition rate used during the measurement was insufficient for the accurate determination of the first inflection within the time interval and the type-K thermocouple used in the measurement did not guarantee the accuracy for the range above $1300^{\circ} \mathrm{C}$.

The precipitation reaction of $\mathrm{M}_{7} \mathrm{C}_{3}$ (pro-eutectic) carbide from the liquid $\mathrm{L}_{2}$ is a strong candidate for the $\mathrm{T}_{\mathrm{R} 1}$ inflection at $1286^{\circ} \mathrm{C}$. The first eutectic reaction, precipitation of austenite dendrites and $\mathrm{M}_{7} \mathrm{C}_{3}$ (eutectic) from the liquid $\mathrm{L}_{3}$, is a candidate for the $\mathrm{T}_{\mathrm{R} 2}$ inflection at $1187^{\circ} \mathrm{C} . \mathrm{T}_{\mathrm{R} 3}$ is a candidate to represent the beginning of the $\mathrm{L}_{4}$ eutectic transformation in $\mathrm{M}_{2} \mathrm{C}$ and austenite.

\subsection{Analysis of carbides}

Considering the three types of carbides, $\mathrm{MC}, \mathrm{M}_{2} \mathrm{C}$, and $\mathrm{M}_{7} \mathrm{C}_{3}$, the chemical composition distribution showed in Figure 7 and the phases indexed at EBSD maps, it is possible to observe a partial solubility of carbide-former elements at one or more carbides, e.g. Mo has a partial solubility at $\mathrm{MC}$ carbides, however, the solubility of $\mathrm{V}$ in $\mathrm{M}_{2} \mathrm{C}$ carbide is lower.

The chemical composition of the carbides was analyzed by EDS. Points and areas selected for the measurements are indicated in Figure 8. Table 5 shows the composition range of the investigated phases. Figure 9 shows the results of an EDS line scan along with different carbides and the mean composition of carbides considering the principal carbideforming elements.

As expected, the carbides in the HEWCI are enriched with vanadium, chromium, and molybdenum, because these elements have a higher affinity for carbon than iron. The proeutectic $(\mathrm{V}, \mathrm{Nb}) \mathrm{C}$ and $\mathrm{M}_{7} \mathrm{C}_{3}$ carbides and the eutectic $\mathrm{M}_{7} \mathrm{C}_{3}$ and $\mathrm{M}_{2} \mathrm{C}$ carbides were depleted in iron in comparison with the matrix, which is in an agreement with data in Table 3 and Figure 8. During the formation of austenite dendrites, molybdenum is rejected into the liquid, enriching it and promoting the precipitation of $\mathrm{M}_{2} \mathrm{C}$ carbide (high Mo phase) at a lower temperature eutectic reaction. According to the results at EDS Line, EDS analysis (Figure 9), the austenite region has low Mo concentration. 


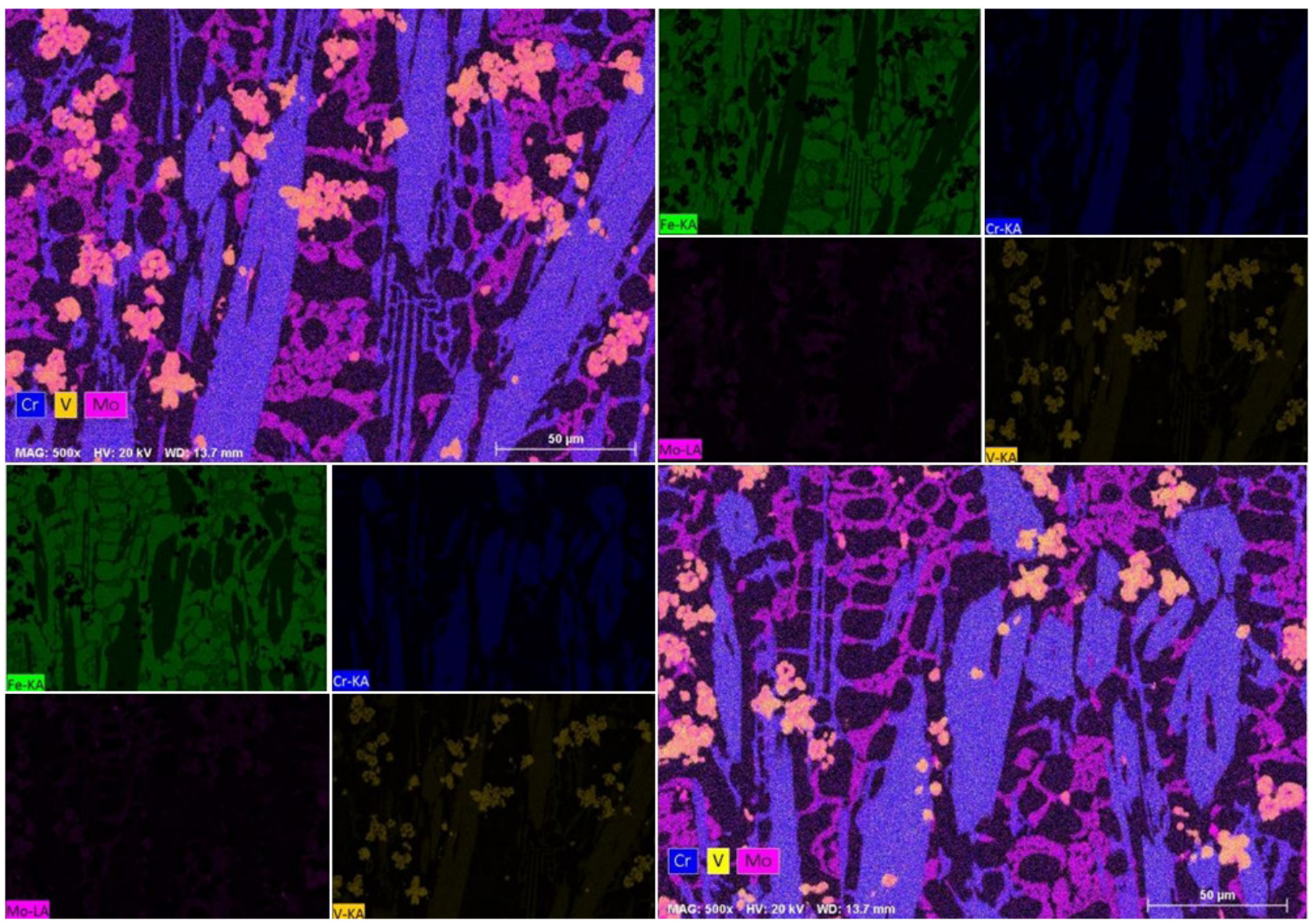

Figure 7. Chemical composition of X-ray mapping.

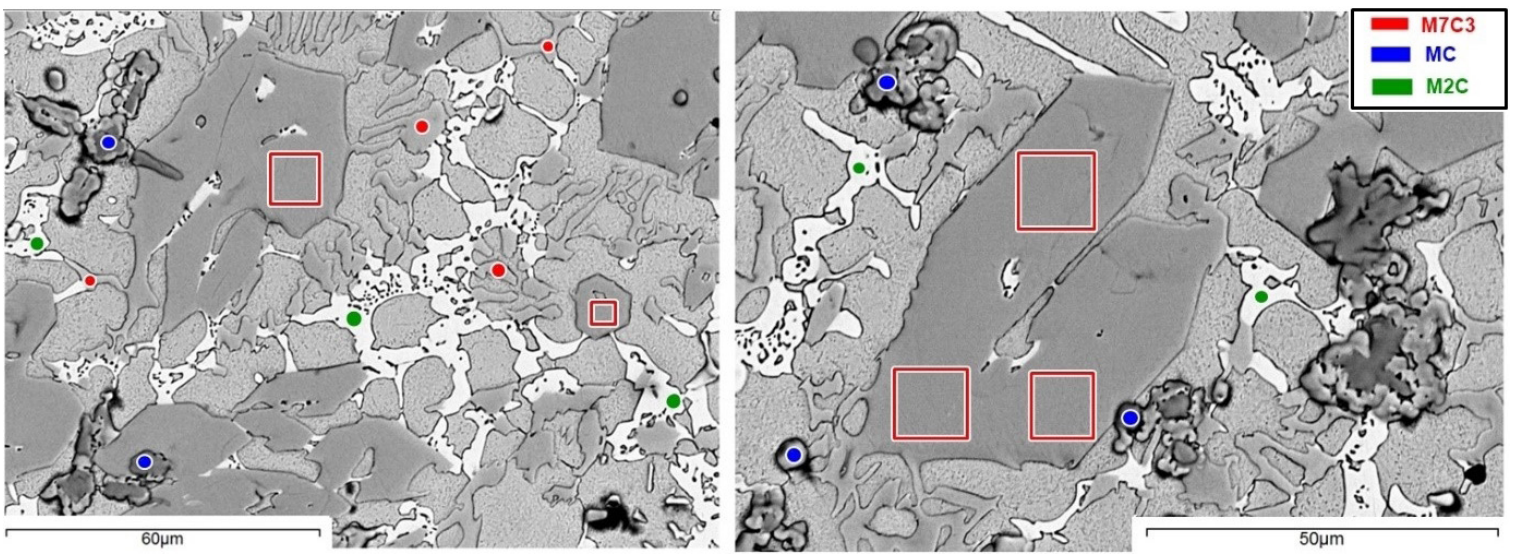

Figure 8. Selected and spotted areas for EDS Analysis - Red marks for $\mathrm{M}_{7} \mathrm{C}_{3}$ carbides, Green marks for $\mathrm{M}_{2} \mathrm{C}$ carbides and Blue marks for MC carbides.

Table 5. Range of chemical Analysis (EDS) of Carbides.

\begin{tabular}{|c|c|c|c|c|c|c|c|c|c|}
\hline & & $\mathrm{C}$ & $\mathrm{Cr}$ & Mo & $\mathbf{N b}$ & $\mathbf{V}$ & Mn & $\mathbf{S i}$ & $\mathbf{F e}$ \\
\hline \multirow{2}{*}{$\begin{array}{l}\mathrm{MC} \\
\text { proeutectic }\end{array}$} & Min & 46.95 & 4.73 & 3.94 & 2.56 & 26.97 & \multirow{2}{*}{-} & \multirow{2}{*}{ - } & 0.57 \\
\hline & Max & 56.97 & 7.70 & 5.98 & 5.93 & 35.71 & & & 1.05 \\
\hline \multirow{2}{*}{$\begin{array}{l}\mathrm{M}_{7} \mathrm{C}_{3} \\
\text { proeutectic }\end{array}$} & Min & 36.13 & 29.51 & 2.06 & \multirow{2}{*}{ - } & 8.73 & 3.90 & \multirow{2}{*}{ - } & 17.36 \\
\hline & Max & 37.96 & 30.57 & 2.19 & & 9.33 & 4.34 & & 17.68 \\
\hline \multirow{2}{*}{$\begin{array}{l}\mathrm{M}_{7} \mathrm{C}_{3} \\
\text { eutectic }\end{array}$} & Min & 35.97 & 26.27 & 3.24 & \multirow[b]{2}{*}{ - } & 6.55 & 4.74 & \multirow{2}{*}{ - } & 18.00 \\
\hline & Max & 40.56 & 28.40 & 4.08 & & 7.74 & 5.33 & & 19.32 \\
\hline \multirow{2}{*}{$\begin{array}{l}\mathrm{M}_{2} \mathrm{C} \\
\text { eutectic }\end{array}$} & Min & 24.22 & 11.32 & 9.40 & \multirow[b]{2}{*}{-} & 2.00 & 6.74 & 6.46 & 34.04 \\
\hline & Max & 26.88 & 12.80 & 10.41 & & 2.59 & 7.58 & 7.27 & 36.80 \\
\hline
\end{tabular}




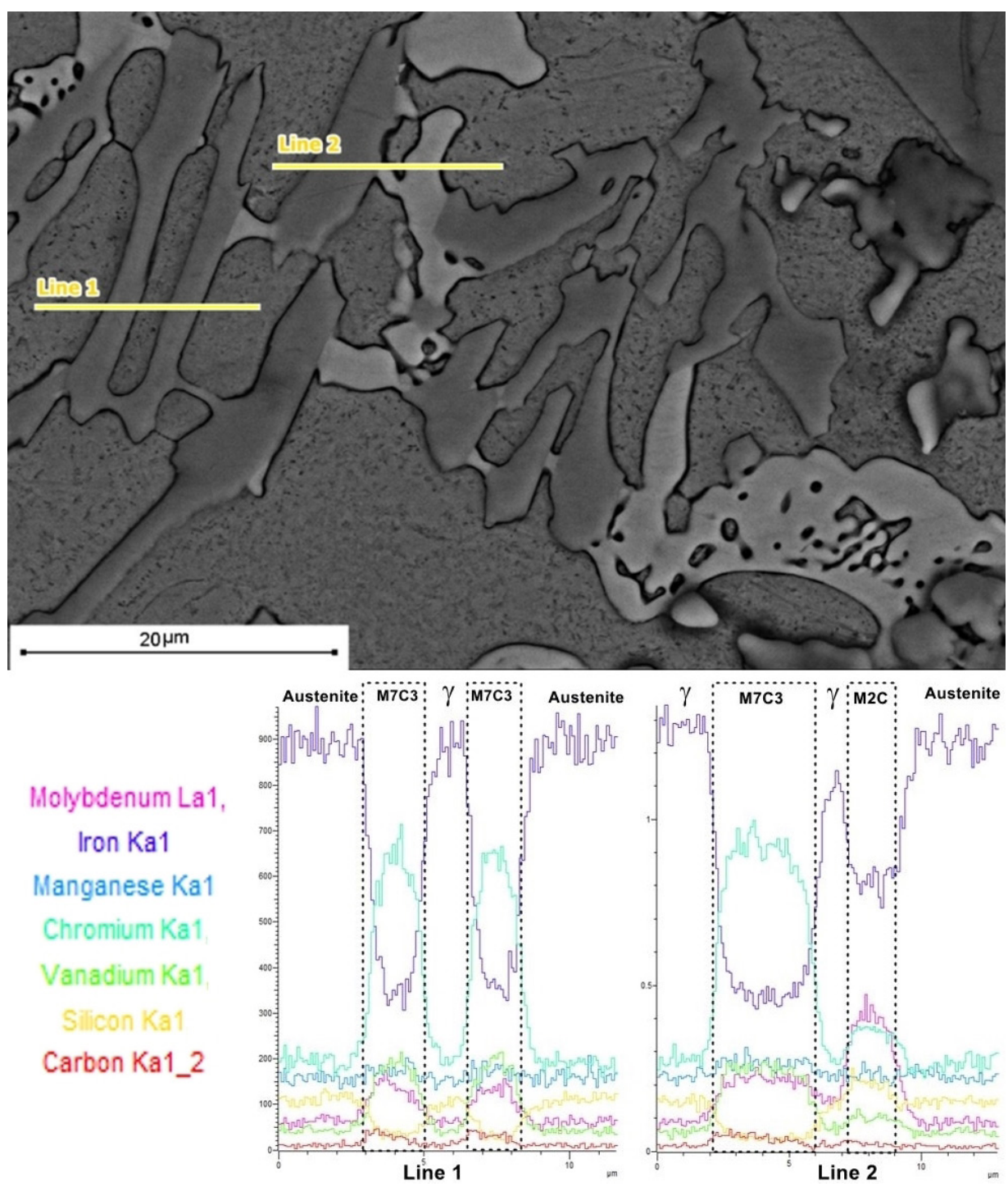

Figure 9. Corresponding chemical profiles along different carbides and matrix.

Literature reports indicate the addition of carbide-forming elements, at concentrations higher than what is currently used, can affect the solidification path and the chemical composition of carbides in abrasion-resistant cast irons. The compositions of primary $\mathrm{M}_{7} \mathrm{C}_{3}$ and eutectic $\mathrm{M}_{7} \mathrm{C}_{3}$ carbides present in $\mathrm{HEWCI}$ are different from the ones suggested by the $\mathrm{Fe}-\mathrm{Cr}-\mathrm{C}$ system due to the addition of carbide-forming elements, $\mathrm{V}$ and Mo. The $\mathrm{Cr}$ and $\mathrm{Fe}$ composition in proeutectic and eutectic $\mathrm{M}_{7} \mathrm{C}_{3}$ carbide decrease with the increment of Mo and $\mathrm{V}$ for this composition. This behavior was also described by previous research of Yamamoto et al. ${ }^{32}$, Chung et al. ${ }^{33}$ and Filipovic et al. ${ }^{34}$.

\section{Conclusion}

In order to develop a new class of abrasion-resistant cast iron, merging concepts of high entropy to conventional metallurgy of high chromium cast iron a modified alloy with more than five carbide-forming elements and configuration entropy at liquid state superior to $-1.5 \mathrm{R}$, was produced in an induction coreless furnace. The solidification and carbides analysis of a complex concentrated alloy, called in this work as High Entropy Cast Iron (HEWCI), have been studied. The results are summarized as follows:

1. MC carbide with a face-centered cubic lattice structure, $\mathrm{M}_{7} \mathrm{C}_{3}$ carbide with an orthorhombic lattice structure and $\mathrm{M}_{2} \mathrm{C}$ with hexagonal lattice structure was formed during solidification. Their lattice structure of carbides was indexed by XRD and EBSD techniques.

2. The cooling curve of HEWCI and phases indexed by diffraction techniques indicate that the possible solidification sequence of the HEWCI is: $\mathrm{L}_{1} \rightarrow \mathrm{MC}$ $+\mathrm{L}_{2}\left(\mathrm{~T}_{\mathrm{R}}\right.$ not detected) $\rightarrow \mathrm{L}_{2} \rightarrow \mathrm{M}_{7} \mathrm{C}_{3}$ (pro-eutectic) $+\mathrm{L}_{3}\left(\mathrm{~T}_{\mathrm{R} 1}\right.$ at $\left.1286^{\circ} \mathrm{C}\right) \rightarrow \mathrm{L}_{3} \rightarrow \gamma+\mathrm{M}_{7} \mathrm{C}_{3}$ (eutectic) + $\mathrm{L}_{4}\left(\mathrm{~T}_{\mathrm{R} 2}\right.$ at $\left.1187^{\circ} \mathrm{C}\right) \rightarrow \mathrm{L}_{4} \rightarrow \gamma+\mathrm{M}_{2} \mathrm{C}\left(\mathrm{T}_{\mathrm{R} 3}\right.$ at $\left.1156^{\circ} \mathrm{C}\right)$.

3. A combination of BSE imaging, EDS and EBSD was capable to identify, analyze and quantify different phases in the microstructure. $\mathrm{MC}, \mathrm{M}_{7} \mathrm{C}_{3}$ and $\mathrm{M}_{2} \mathrm{C}$ 
carbides were characterized and the final HEWCI as-cast microstructure is composed of approximately $50 \%$ of austenite and $50 \%$ of different carbides.

\section{Acknowledgements}

The authors acknowledge the Brazilian research agencies $\mathrm{CNPq}$ and CAPES, for financial support, the Microcopy and Microanalysis center technical staff from Federal University of Rio Grande do Sul for the BSE images end EDS results, and Professor Sergio Barra and Professor Nicolau Castro from Federal University of Rio Grande do Norte to collaborate with the XRD diffractogram, EBSD-maps results.

\section{References}

1. Doğan ÖN, Hawk JA, Laird G. Solidification structure and abrasion resistance of high chromium white irons. Metall Mater Trans, A Phys Metall Mater Sci. 1997;28(6):1315-28.

2. Laird G, Doğan ÖN. Solidification structure versus hardness and impact toughness in high-chromium white cast irons. Int J Cast Met Res. 1996;9(2):83-102.

3. Hashimoto M, Kubo O, Matsubara Y. Analysis of carbides in multi-component white cast iron for hot rolling mill rolls. ISIJ Int. 2004;44(2):372-80.

4. Matsubara Y, Sasaguri N, Shimizu K, Kon Yu S. Solidification and abrasion wear of white cast irons alloyed with $20 \%$ carbide forming elements. Wear. 2001;250-251(1-12):502-10.

5. Cantor B, Chang ITH, Knight P, Vincent AJB. Microstructural development in equiatomic multicomponent alloys. Mater Sci Eng A. 2004;375-377:213-8.

6. Yeh J-W, Chen S-K, Lin S-J, Gan J-Y, Chin T-S, Shun T-T, et al. Nanostructured high-entropy alloys with multiple principal elements: novel alloy design concepts and outcomes. Adv Eng Mater. 2004;6(5):299-303.

7. Miracle DB, Senkov ON. A critical review of high entropy alloys and related concepts. Acta Mater. 2017;122:448-511.

8. Gorsse S, Couzinié J, Miracle DB. From high-entropy alloys to complex concentrated alloys Des alliages à haute entropie aux alliages concentrés complexes. C R Phys. 2018;19(8):721-36.

9. Ye YF, Wang Q, Lu J, Liu CT, Yang Y. High-entropy alloy: challenges and prospects. Mater Today. 2015;19(6)

10. Yeh J-W. Physical metallurgy of high-entropy alloys. JOM. 2015;67(10):2254-61.

11. Yeh JW. Alloy design strategies and future trends in high-entropy alloys. JOM. 2013;65(12):1759-71.

12. Ye YF, Wang Q, Lu J, Liu CT, Yang Y. High-entropy alloy: challenges and prospects. Mater Today. 2016;19(6):349-62.

13. Gorsse S, Miracle DB, Senkov ON. Mapping the world of complex concentrated alloys. Acta Mater. 2017;135:177-87.

14. George EP, Raabe D, Ritchie RO. High-entropy alloys. Nat Rev Mater. 2019;4(8):515-34.

15. Tsai MH. Three strategies for the design of advanced highentropy alloys. Entropy (Basel). 2016;18(7)

16. Raabe D, Tasan CC, Springer H, Bausch M. From high-entropy alloys to high-entropy steels. Steel Res Int. 2015;86(10):1127-38.

17. Pushin VG, Kuranova NN, Nikolaeva NV, Uksusnikov AN, Ustyugov YM, Belosludtseva ES, et al. Specific features of the phase composition and structure of a high-strength multi- component $\mathrm{Fe}-\mathrm{W}-\mathrm{Mo}-\mathrm{Cr}-\mathrm{V}-\mathrm{Si}-\mathrm{Mn}-\mathrm{C}$ steel synthesized via laser remelting. Adv Eng Mater. 2015;17(10):1504-10.

18. Wang YP, Li DY, Parent L, Tian H. Improving the wear resistance of white cast iron using a new concept - High-entropy microstructure. Wear. 2011;271(9-10):1623-8.

19. Wang YP, Li DY, Parent L, Tian H. Performances of hybrid high-entropy high-Cr cast irons during sliding wear and air-jet solid-particle erosion. Wear. 2013;301(1-2):390-7.

20. Lu Y, Gao X, Jiang L, Chen Z, Wang T, Jie J, et al. Directly cast bulk eutectic and near-eutectic high entropy alloys with balanced strength and ductility in a wide temperature range. Acta Mater. 2017;124:143-50.

21. Nagase T, Kakeshita T, Matsumura K, Nakazawa K, Furuya S, Ozoe N, et al. Development of Fe-Co-Cr-Mn-Ni-C high entropy cast iron (HE cast iron) available for casting in air atmosphere. Mater Des. 2019;184:108172.

22. Liu S, Zhou Y, Xing X, Wang J, Ren X, Yang Q. Growth characteristics of primary $\mathrm{M} 7 \mathrm{C} 3$ carbide in hypereutectic FeCr-C alloy. Sci Rep. 2016;6(1):32941.

23. Wu H-Q, Sasaguri N, Hashimoto M, Matsubara Y. Type and morphology of carbides precipitated in multi-component white cast iron. J Japan Foundrymen'S Soc. 1995;67(1):49-55.

24. Boccalini M, Corrêa AVO, Goldenstein H. Rare earth metal induced modification of $\gamma$-M2C, $\gamma$-M6C, and $\gamma$-MC eutectics in as cast M2 high speed steel. Mater Sci Technol. 1999;15(6):621-6.

25. Zhou X-F, Liu D, Zhu W-L, Fang F, Tu Y-Y, Jiang J-Q. Morphology, microstructure and decomposition behavior of $\mathrm{M} 2 \mathrm{C}$ carbides in high speed steel. J Iron Steel Res Int. 2017;24(1):43-9.

26. Sasaguri N, Yokomizo Y, Mutaguchi T, Mitsuo Hashimoto YM. Crystallization behavior of carbides in hypereutectic multi-component white cast iron with high carbon content. J Japan Foundry Eng Soc. 2005;77(9):629-36.

27. Wu H, Sasaguri N, Matsubara Y, Hashimoto M. Solidification sequence of multi-component white cast iron. J Japan Foundry Eng Soc. 1996;68(8):637-43.

28. Thorpe WR, Chicco B. The Fe-rich corner of the metastable C-Cr-Fe liquidus surface. Metall Trans, A, Phys Metall Mater Sci. 1985;16(9):1541-9.

29. Imurai S, Thanachayanont $C$, Pearce JTH, Tsuda K, Chairuangsri T. Effects of Mo on microstructure of as-cast 28 wt. \% Cr-2.6 wt.\% C-(0-10) wt.\% Mo irons. Mater Charact. 2014;90:99-112.

30. DeMello JDB, Durand-Charre M, Hamar-Thibault S. Solidification and solid state transformations during cooling of chromiummolybdenum white cast irons. Metall Trans, A, Phys Metall Mater Sci. 1983;14(9):1793-801. https://doi.org/10.1007/BF02645549.

31. Ikeda M, Umeda T, Tong CP, Suzuki T, Niwa N, Kato O. Effect of molybdenum addition on solidification structure, mechanical properties and wear resistivity of high chromium cast irons. ISIJ Int. 1992;32(11):1157-62. https://doi.org/10.2355/ isijinternational.32.1157.

32. Yamamoto K, Inthidech S, Sasaguri N, Matsubara Y. Influence of mo and $\mathrm{w}$ on high temperature hardness of M7C 3 carbide in high chromium white cast iron. Mater Trans. 2014;55(4):684-9.

33. Chung RJ, Tang X, Li DY, Hinckley B, Dolman K. Microstructure refinement of hypereutectic high $\mathrm{Cr}$ cast irons using hard carbide-forming elements for improved wear resistance. Wear. 2013;301(1-2):695-706

34. Filipovic M, Romhanji E, Kamberovic Z. Chemical composition and morphology of $\mathrm{M} 7 \mathrm{C} 3$ eutectic carbide in high chromium white cast iron alloyed with vanadium. ISIJ Int. 2012;52(12):2200-4. 